\title{
MONTE CARLO SIMULATION OF RADIOACTIVE DECAY
}

\author{
Sahajpreet Singh \\ Student of B.Sc. (Hons.) Physics, Department of Physics \\ Sri Guru Tegh Bahadur Khalsa College, University of Delhi, Delhi, India
}

\begin{abstract}
Most of the f-block element's nucleus is not stable, to gain stability they break down in two or more daughter nucleus. For radioactive decay simulation, the fact nuclei decay is sufficient. We will use the Monte Carlo method which is based on random numbers, although radioactive decay is also a random process as we don't know accurately which one nuclei will be going to decay next. To do real-time experiments to study radioactivity is dangerous and very costly. The emitted radiations in this process are harmful to human beings and nature but although as its application it has uses in especially cancer treatment.
\end{abstract}

Keywords- Radioactive decay, Half-mean life, simulation, Probability, Random numbers

\section{INTRODUCTION}

Firstly, Henri Becquerel seen that uranium emits radiations using a photographic plate and these radiations were sensitive about the magnetic field. Some of them are positively changed, some of them negatively and some of them didn't affect by the magnetic field which was identified as alpha particle $\left(\mathrm{He}^{2+}\right)$, beta particle(negatively changed that is equal to $\mathrm{e}=-1.6 \times 10^{-19} \mathrm{C}$ ) and gamma rays(neutral high energy rays) respectively, see Fig.1.

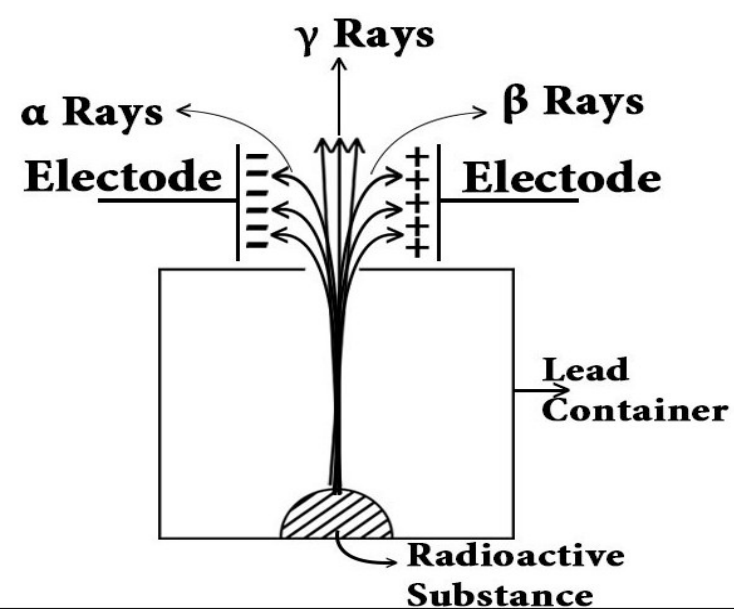

Fig.1 Radioactive element under electric or magnetic field
After that, there's a lot of contribution of Marie Curie in the field of radioactivity as she also known as "Mother of Modern Physics" gives the term radioactivity. Although Ernest Rutherford is also did many experiments to study of radioactive elements.

A) Radioactivity : The emission of ionizing radiation or particle caused by the spontaneous disintegration of atomic nuclei is called radioactivity which is a property of radioactive nucleus. We know that the rate of decay of nuclei is directly proportional to the initial number of nuclei. By solving the differential equation we got,

$$
\begin{aligned}
& \frac{d N}{d t} \propto-N \\
& \frac{d N}{d t}=-\lambda N
\end{aligned}
$$

By solving the differential equation, from $\mathrm{t}=0$ to same $\mathrm{t}$

$$
N(t)=N_{0} e^{-\lambda t}
$$

(Equation 1)

Where $\lambda$ is "decay constant" for that particular radioactive element.

B) Half Life : The rate of decay is used to determine in the terms of half-life. The half-life of radioactive nuclei is defined as the time it takes for one-half of the atoms of a radioactive material to disintegrate. Half-lives for various radioisotopes can range from a $10^{-3}$ seconds to $10^{9}$ years.

At $\mathrm{t}=\mathrm{t}_{1 / 2}$,

$$
\begin{gathered}
N(t)=\frac{N_{0}}{2}=N_{0} e^{-\lambda t} \\
N(t)=N_{0} e^{-\lambda t} \\
t_{1 / 2}=\frac{0.693}{\lambda}
\end{gathered}
$$

(Equation 2) 


\section{International Journal of Engineering Applied Sciences and Technology, 2020 \\ Vol. 5, Issue 5, ISSN No. 2455-2143, Pages 86-90 \\ Published Online September 2020 in IJEAST (http://www.ijeast.com)}

C) Mean Life : Mathematically, mean life is defined as ratio total life of all nucleus and the total number of the nucleus. We can find out mean life by just doing small calculation as -

$$
\begin{gathered}
\tau=\frac{\int_{0}^{\infty} t d N}{\int_{0}^{\infty} d N} \\
\tau=\frac{\int_{0}^{\infty} t \lambda N_{0} e^{-\lambda t} d t}{\tau=\frac{\int_{0}^{\infty} \lambda N_{0} e^{-\lambda t} d t}{\int_{0}^{\infty} t e^{-\lambda t} d t}} \\
\int_{0}^{-\lambda t} d t \\
\tau=\frac{1}{\lambda}
\end{gathered}
$$

(Equation 3)

D) Probability of decay of a nuclei in next unit time : It is independent of the total number of the nucleus but only depends on the decay constant.

Let at any time t, $N(t)=N_{0} e^{-\lambda t}$

and at time $(\mathrm{t}+1), \quad N(t+1)=N_{0} e^{-\lambda(t+1)}$

Thus, probability of decay of a nuclei in next unit time= No. of decayed nuclei in unit time

No. of total nuclei at time $\mathrm{t}$

$$
\begin{gathered}
P=\frac{N(t)-N(t+1)}{N(t)} \\
P=1-\frac{N(t+1)}{N(t)} \\
P=1-\frac{N_{0} e^{-\lambda(t+1)}}{N_{0} e^{-\lambda t}} \\
P=1-e^{-\lambda}
\end{gathered}
$$

(Equation 4)
Now we are little familiar with radioactive decay, in next section, we will see how we can simulate this phenomenon using any computer programming language and software like Python3, Julia, Scilab, Matlab and many more.

\section{SIMULATION METHOD}

To simulate radioactive decay we will use Monte Carlo Approximation. It's based on random numbers with applications like - integration, traveling salesman problem, artificial intelligence for games and simulation of many real and quantum world problems.

Let the initial number of the nucleus of any radioactive element is $\mathrm{N}_{0}$ then instead of taking some coins or dice, I will use computer-generated random numbers because it gives us more choice to choose the probability of decay. I will generate $\mathrm{N}_{0}$ random numbers between 0 and 1 and decide a number $\lambda$ (which will be identified as decay constant) between 0 and 1 . If $N^{\prime}$ random numbers are less than $\lambda$ then that $N$ ' number of the nucleus will decay. Now, I left with $\mathrm{N}_{0}-\mathrm{N}$ ' number of the nucleus, so next time there will be $\mathrm{N}_{0}-\mathrm{N}$ ' random numbers between 0 and 1 and again $N$ ” numbers are less then $\lambda$ will decay. And this process will go on until no nuclei left. In this process, we assume whenever the process repeats it's 1 unit time. By using this data we can easily plot it and compare with the analytical plot.

Now, by using $\lambda$ as a random number as an unknown radioactive element's decay constant we can calculate it using out graph and concept of half-life. For this, first plot the decay of nucleus with time and note down at what time the number of nuclei are half of its initial value and put in this formula -

$$
\lambda=\frac{\log _{e}(2)}{t_{1 / 2}}
$$

\section{RESULTS AND DISCUSSION}

Firstly, I take 200 nuclei and decay constant $=0.2$. Then the simulation and analytic results are in the following table -

\begin{tabular}{|c|c|c|}
\hline $\mathrm{t}$ & $\begin{array}{c}\mathrm{N}(\mathrm{t}) \text { (Using Random } \\
\text { Numbers Method) }\end{array}$ & $\begin{array}{c}N(t)=N_{0} e^{-\lambda t} \\
\text { (Using Analytic Eq.) }\end{array}$ \\
\hline 0 & 200 & 200 \\
\hline 1 & 160 & 164 \\
\hline 2 & 126 & 134 \\
\hline 3 & 105 & 110 \\
\hline 4 & 81 & 90 \\
\hline 5 & 71 & 74 \\
\hline 6 & 59 & 60 \\
\hline
\end{tabular}


International Journal of Engineering Applied Sciences and Technology, 2020

Vol. 5, Issue 5, ISSN No. 2455-2143, Pages 86-90

Published Online September 2020 in IJEAST (http://www.ijeast.com)

\begin{tabular}{|c|c|c|}
\hline 7 & 51 & 49 \\
\hline 8 & 44 & 40 \\
\hline 9 & 35 & 33 \\
\hline 10 & 30 & 27 \\
\hline 11 & 25 & 22 \\
\hline 12 & 21 & 18 \\
\hline 13 & 19 & 15 \\
\hline 14 & 18 & 12 \\
\hline 15 & 13 & 10 \\
\hline
\end{tabular}

A) Then I tried to fix decay constant as $\lambda=0.2$ and taken $\mathrm{N}_{0}$ in range $10^{2}$ to $10^{4}$ and plot it along with analytic expected values.

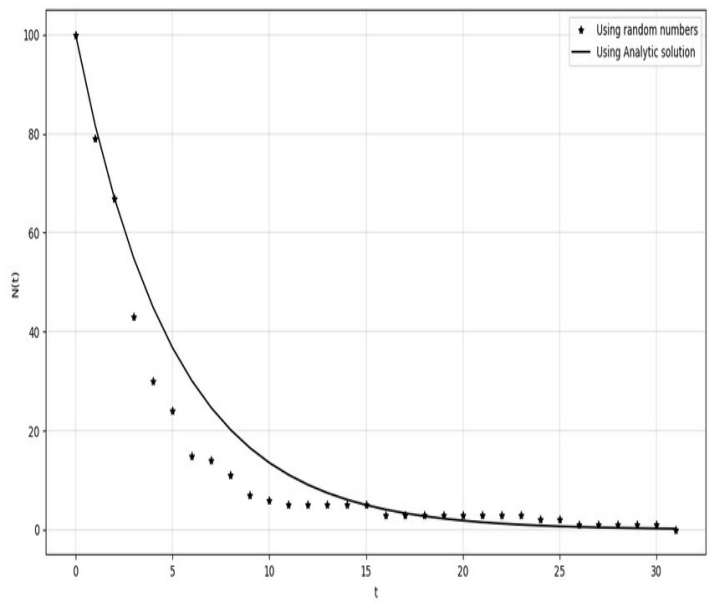

Fig. $2 \mathrm{~N}_{0}=100$ and decay constant $=0.2$

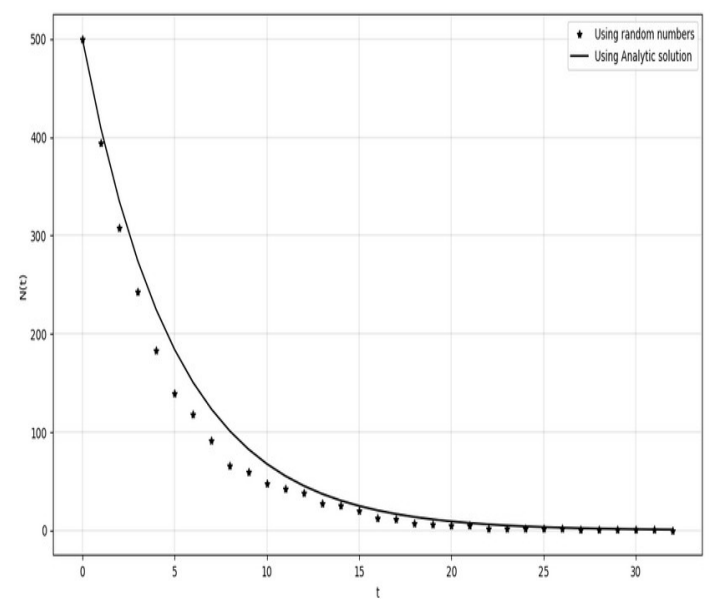

Fig. $3 \mathrm{~N}_{0}=500$ and decay constant $=0.2$

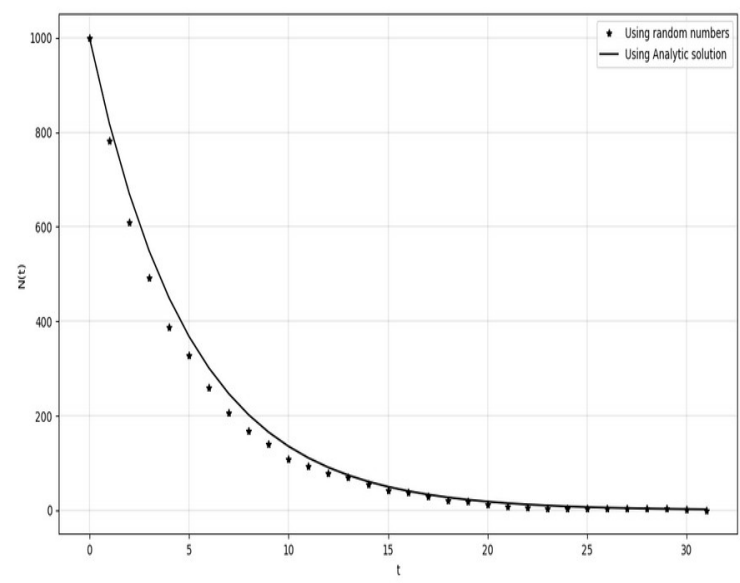

Fig. $4 \mathrm{~N}_{0}=1 \mathrm{~K}$ and decay constant $=0.2$

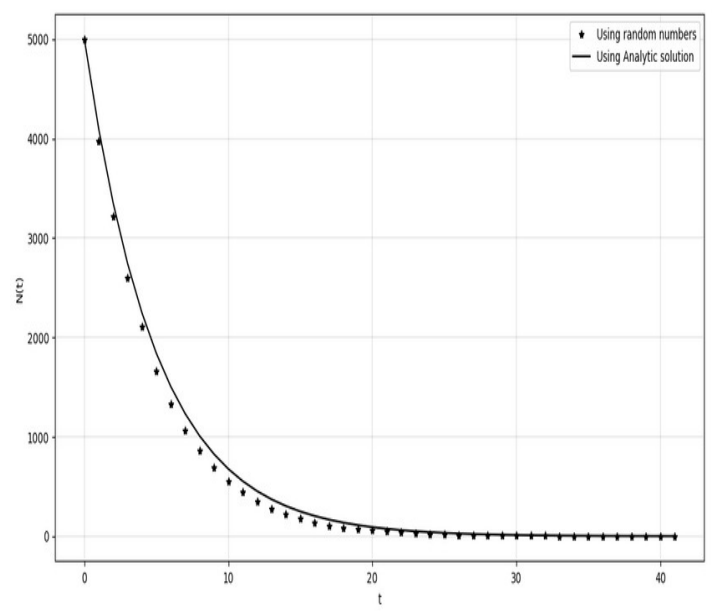

Fig. $5 \mathrm{~N}_{0}=5 \mathrm{~K}$ and decay constant $=0.2$

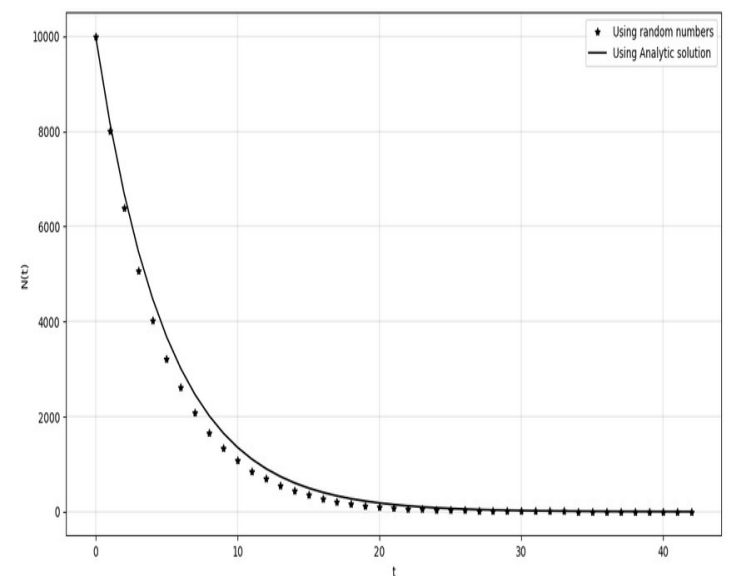

Fig. $6 \mathrm{~N}_{0}=10 \mathrm{~K}$ and decay constant $=0.2$ 


\section{International Journal of Engineering Applied Sciences and Technology, 2020 \\ Vol. 5, Issue 5, ISSN No. 2455-2143, Pages 86-90 \\ Published Online September 2020 in IJEAST (http://www.ijeast.com)}

Here from Fig.2 to Fig.6 we can see as we increase the number of the initial nuclei the simulated graph(star) approaches analytic curve for given $\mathrm{N}_{0}$ and $\lambda$.

B) Now we know $\mathrm{N}_{0}$ should be large enough so that simulated data approaches to analytic results. So, this time I took $\mathrm{N}=10^{5}$ and used different decay constant as $\lambda=0.05,0.1$, $0.2 \ldots$

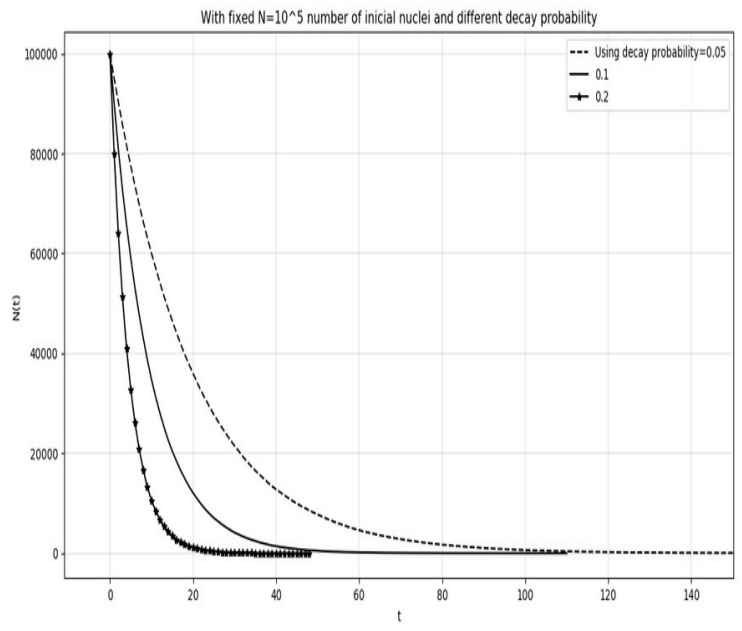

C) This time, I will take decay constant as a computergenerated random as we don't know about decay constant of an unknown radioactive substance. Now our aim is to find out the decay constant. So by plot, these computer-generated data get

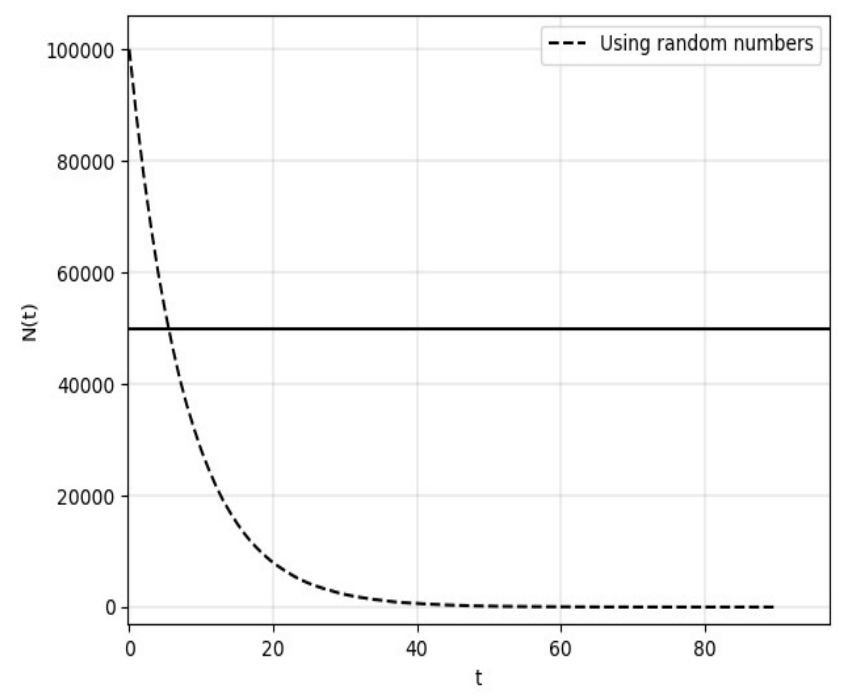

Fig.7 $\mathrm{N}_{0}=10^{5}$ and decay constant is unknown

In the Fig.7 dotted line is my simulation data and the solid line denotes half number of initial nuclei and at intersection point, the time is simply half-life. If I know half-life then I can easily evaluate decay constant $\lambda$. Now I am just going to zoom the intersect area to get the value of time when I left with half of initial nucleus.

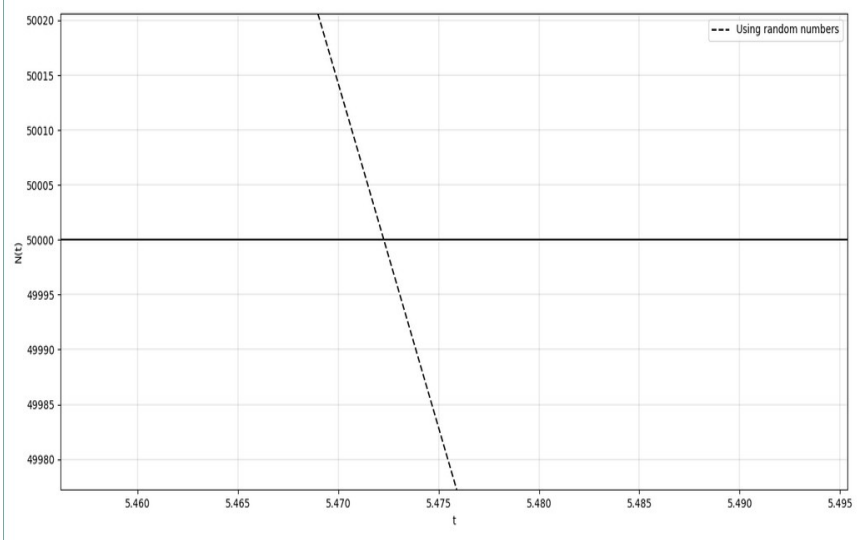

AH十

Fig.8 Intersection point (zoomed) of graph in Fig.7

We can see in fig.8 that the point intersection is $\left(5.47228,5^{*} 10^{4}\right)$. That means the half-life is 5.47228 then the value of $\lambda$ is given by -

$$
\begin{gathered}
\lambda=\frac{\log _{e}(2)}{t_{1 / 2}} \\
\lambda=\frac{0.693147181}{5.47228}=0.12667 \text { unit }^{-1}
\end{gathered}
$$

\section{CONCLUSION AND FURTHER IDEAS}

Bakaç et al.(2011) used coins in his work to simulate radioactive decay process, then we can either use $0,0.5$ or 1 as decay constant. Also one more disadvantage is that it's not easy to deal with large number of coins, say $5 \mathrm{~K}$ coins. So doing it with computer based algorithms save time and have an advantage to choose the decay probability between 0 and 1 , that means infinite number of choices to take decay probability/constant $\lambda$.

By simulate the radioactive decay using computer-generated random number, it's easy to plot it using Matplotlib (However to plot a large data using graph and pencil is not an easy task).

\section{IMPORTANT POINTS TO BE NOTED -}

(I) If we take large enough number of nuclei, our simulated data approaches to the theoretical one.

(II) By analytic solution sometimes we get float values of $\mathrm{N}(\mathrm{t})$ which is not possible, then what we do is called rounding off.

After getting the unknown value of decay constant using Fig.7, I just printed the random value that the computer 


\section{International Journal of Engineering Applied Sciences and Technology, 2020 \\ Vol. 5, Issue 5, ISSN No. 2455-2143, Pages 86-90 \\ Published Online September 2020 in IJEAST (http://www.ijeast.com)}

generated and is same as the calculated one $(=0.12667)$ with accurate till 3rd decimal place. One can also try to plot different probability distributions like - Normal and Poisson Distribution(Which will build a better understanding of probabilistic nature of radioactive decay).

\section{ACKNOWLEDGMENT}

Firstly, thank you God for the beautiful world and Priceless life.

I wish to thank various people for being very supportive to me during this project are my college professors, friends and my family. It's my one of the biggest dream to write an article in a journal that is going to be true, I also want to thank my mother(Simarpal Kaur) and grandmaa(Gurjinder Kaur) for their blessings.

I am vary thankful to all from bottom of my heart and a lot of love from my side.

\section{REFERENCES}

[1] BECQUEREL, J., 1948. Discovery of Radioactivity. Nature, 161(4094), pp.609-609.

[2] Radvanyi, P. and Villain, J., 2017. The discovery of radioactivity. Comptes Rendus Physique, 18(9-10), pp.544550.

[3] Bakaç, M., Taşoğlu, A. and Uyumaz, G., 2011. Modeling radioactive decay. Procedia - Social and Behavioral Sciences, 15, pp.2196-2200.

[4] Schreider, Y., Tee, G. and Henney, A., 1967. The Monte Carlo Method: The Method of Statistical Trials. Physics Today, 20(1), pp.129-129.

[5] Hunter, J., 2007. Matplotlib: A 2D Graphics Environment. Computing in Science \& Engineering, 9(3), pp.90-95.

[6] Grandine, T., 1990. The Numerical Methods Programming Projects Book. Oxford: Oxford University Press.

[7] Monsef, Y., 1998. Modelling and Simulation of Complex Systems: Methods, Techniques and Tools. SIMULATION, 70(1), pp.59-59.

[8] Heisenberg, W., n.d. Nuclear Physics.

[9] Bender.astro.sunysb.edu. 2020. [online] Available at: $<$ http://bender.astro.sunysb.edu/classes/numerical_methods/le ctures/monte-carlo.pdf> [Accessed 19 September 2020].

[10] Sites.science.oregonstate.edu. 2020. Problem: Spontaneous Decay Simulation. [online] Available at: <http://sites.science.oregonstate.edu/ landaur/nacphy/ComPh ys/MONTE/mc3/node6.html> [Accessed 19 September 2020]. [11] Robson, J., 1950. Radioactive Decay of the Neutron. Physical Review, 78(3), pp.311-312.

[12] Matplotlib.org. 2020. Matplotlib: Python Plotting Matplotlib 3.3.2 Documentation. [online] Available at: <https://matplotlib.org/> [Accessed 19 September 2020]. 